\title{
The international landscape of positive psychology research: A systematic review
}

\author{
Heejin Kim · Kathryn Doiron · Meg A. Warren · Stewart I. Donaldson
}

\begin{abstract}
Since positive psychology originated in 1998 as an organized stream of inquiry in the United States, it has inspired new theory and research on human flourishing across the world. The current systematic review presents an overview of (a) the prevalence of scientific research in positive psychology across five continents and 63 countries, (b) the characteristics of the research, including methodology and topics, and (c) the influence of positive psychology in expanding established lines of research in new ways. Through an analysis of 863 peer-reviewed positive psychology articles, this review attempts to map the international landscape of positive psychology research. Further, it responds to relevant critiques of the field, confirming some and dispelling others. Finally, recommendations are shared for future directions to build a more culturally responsive field of positive psychology that is committed to the advancement of flourishing and wellbeing in the global context.
\end{abstract}

Keywords: positive psychology, wellbeing, optimal functioning, happiness, international, global, cross-cultural, diversity

\section{Introduction}

Since the inception of the positive psychology movement in 1998, scholarship in the area has grown in leaps and bounds in breadth of research, as well as reach across the world. The positive psychology perspective advocates a shift in the lens with which the world is viewed, i.e., one characterized by opportunity for growth (e.g., post-traumatic growth: Tedeschi, Blevins, \& Riffle, 2017) rather than mired by problems (e.g., post-traumatic stress: Yehuda, 2002). In contrast to predominant psychological research that is preoccupied with depression and turmoil, it looks to what causes individuals to thrive. Positive psychology has begun to create a roadmap for building positive qualities (e.g., resilience: Luthar \& Cicchetti, 2000) as a complement to reducing negative influences (e.g., peer pressure: Borsari \& Carey, 2001).

This broad shift in perspective has opened up the space to pose new research questions, investigate previously ignored positive phenomena, and approach well-established areas of research with fresh eyes. Consequently, over the last two decades, this movement has inspired a plethora of research across a wide range of areas of scholarship. As this movement has made ripples around the world, we attempt to take stock and ask the question: how have scholars across the globe interpreted and engaged this perspective? What are the unique characteristics of the extant research influenced by this perspective? What are some of the impactful contributions that have emerged?

The purpose of this review is to address these questions by examining the research in positive psychology across the world in its first 17 years, from 1998 to 2014. To do so, we map the global landscape of positive psychology research using three main foci: prevalence, characteristics, and 
research topics. The prevalence of positive psychology research is operationalized as the extent to which peer-reviewed empirical articles have been published in and across regions. The characteristics of this research are mapped by examining the broad trends of the research methodologies employed. Finally, we sample the prominent topics framed under the positive psychology umbrella that have made meaningful contributions around the world. We partially anchor our analyses around the early criticisms about positive psychology being an elite Western phenomenon (e.g., Christopher \& Hickinbottom, 2008), to examine the extent to which these critiques have been addressed. These first 17 years signify positive psychology's nascence when the field had about 2,000 articles in our database of positive psychology articles and we believe that understanding the trend in the initial years can provide reflections on the past, as well as guidance for the future.

The current review is the first attempt to offer a bird's eye view of the broad trends in positive psychology research across the world. Thus, it facilitates understanding of the role of regional contributions (where the research was conducted) in the larger international landscape of positive psychology. Such an analysis of the state of positive psychology promises to be instructive on trends and key areas of development, and encourage new research questions and directions. While the current study does not compare the status of positive psychology research across cultures, it provides a snapshot of the state of positive psychology in various geographic regions, which, in turn, serves to map the global presence and progress of the field as a whole. Thus, the current review hopes to spark conversations across regions in further advancing the field.

\section{Background}

Before we assess the influence of positive psychology, it is useful to revisit the scope of the field. While the early and most prominent definition of positive psychology emphasized the study of wellbeing and happiness (Seligman \& Csikszentmihalyi, 2000), the positive psychology perspective has influenced a broad range of scholarship, across multiple levels of analysis, inspiring research on virtue (e.g., Dahlsgaard, Peterson, \& Seligman, 2005), meaning (e.g., King, Heintzelman, \& Ward, 2016), gratitude (e.g., Watkins \& Bell, 2017), positive emotions (e.g., Shiota, Yee, O'Neil, \& Danvers, 2017), resilience (e.g., Richardson, 2002), positive relationships (e.g., Warren, Donaldson, \& Lee, 2017), positive youth development (e.g., Shek, Sun, \& Merrick, 2013), and positive organizations (e.g., Warren, Donaldson, \& Luthans, 2017), among many others. Therefore, despite a relatively short history, positive psychology has influenced research across most sub-areas of psychology and beyond, including education, management, coaching, therapy, public health, social services, philosophy, and political science (Donaldson, Csikszentmihalyi, \& Nakamura, 2011).

Global presence: what is known and what is not. Although the positive psychology movement originated in the United States (Seligman \& Csikszentmihalyi, 2000), there is now a vibrant community of researchers across the world. A recent review showed that positive psychology scholarship was found to be published in over 46 countries (Donaldson, Dollwet, \& Rao, 2015). The global influence and popularity of positive psychology has grown to such a large extent that in addition to contributions in mainstream psychology journals, new journals dedicated to indigenous positive psychology scholarship are being developed (e.g., the Middle East and North Africa: Middle East Journal of Positive Psychology; India: Indian Journal of Positive Psychology). 
Table 1. Illustrative sample of associations and degree programs by continent

\begin{tabular}{|c|c|c|}
\hline & Associations & Courses and Degrees \\
\hline Europe & 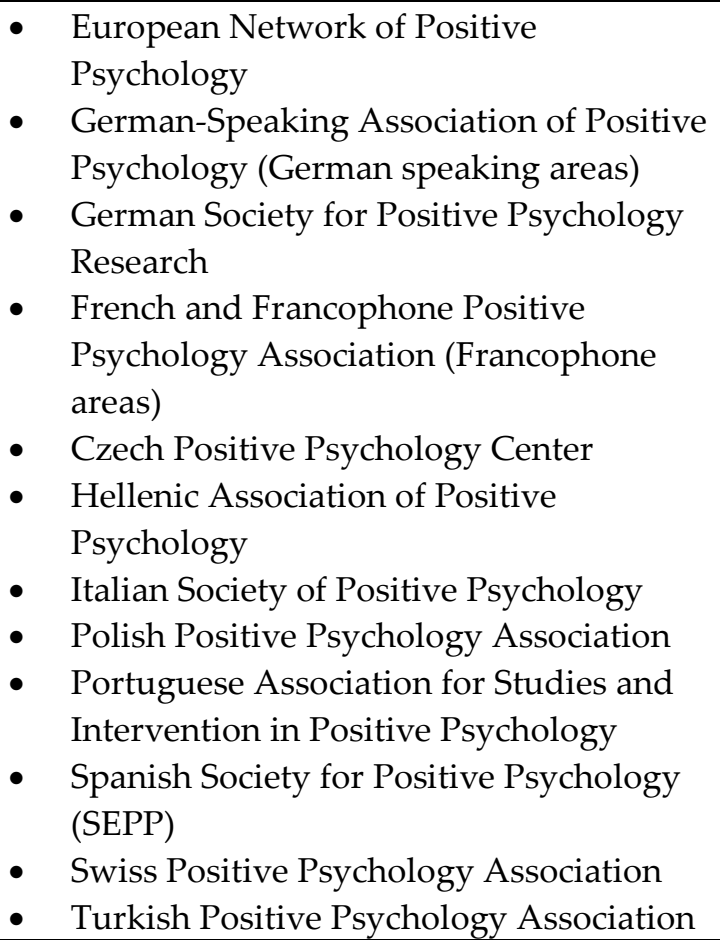 & $\begin{array}{l}\text { - } \text { Oslo Summer School (Norway) } \\
\text { - } \quad \text { Anrhus University (Denmark) } \\
\text { - University (The Netherlands) } \\
\text { - } \quad \text { Universidade de Lisboa (Portugal) } \\
\text { - University (Spain) } \\
\text { University of East London; City } \\
\text { of Glasgow; Middlesex University } \\
\text { London; Anglia Ruskin } \\
\text { University; Buckinghamshire } \\
\text { New University (UK) }\end{array}$ \\
\hline Asia & $\begin{array}{ll}\text { - } & \text { Asian Center for Applied Positive } \\
\text { Psychology } \\
\text { - Global Chinese Positive Psychology } \\
\text { Association } \\
\text { - National Positive Psychology } \\
\text { - } \text { Association, India } \\
\text { - Infor Positive Psychology Association } \\
\end{array}$ & 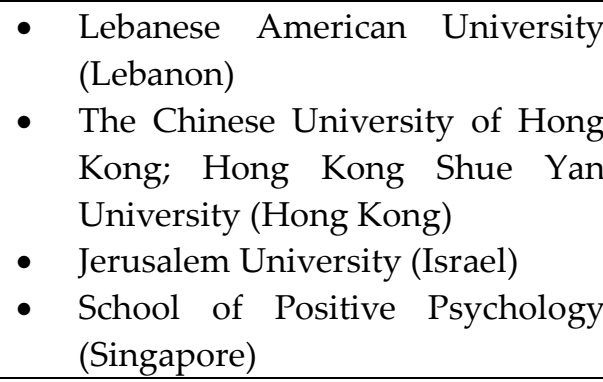 \\
\hline Ame & $\begin{array}{l}\text { - Associação de Psicologia Positiva da } \\
\text { América Latina (Latin America) } \\
\text { - Western Positive Psychology Association } \\
\text { - Canadian Positive Psychology } \\
\text { Association } \\
\text { - Informal groups in Mexico and Brazil }\end{array}$ & $\begin{array}{l}\text { - Instituto Chileno de Psicologia } \\
\text { Positiva (Chile) } \\
\text { Universidad Iberoamericana } \\
\text { (Mexico) } \\
\text { - TechMillenio University (Mexico) } \\
\text { - Claremont Graduate University; } \\
\text { University of Pennsylvania; } \\
\text { University of Utah; Harvard } \\
\text { University; Stanford University; } \\
\text { University of California Los } \\
\text { Angeles [UCLA] Extension; } \\
\text { University of Michigan, Case } \\
\text { Western Reserve University, } \\
\text { University of Missouri (US) }\end{array}$ \\
\hline Oceania & $\begin{array}{l}\text { - New Zealand Association of Positive } \\
\text { Psychology }\end{array}$ & $\begin{array}{l}\text { - University of Sydney; University } \\
\text { of Melbourne: RMIT University; } \\
\text { TAFE South Australia }\end{array}$ \\
\hline Africa & & $\begin{array}{lll}- & \begin{array}{l}\text { North-West University } \\
\text { Africa) }\end{array} & \\
\end{array}$ \\
\hline $\begin{array}{l}\text { International/ } \\
\text { Global }\end{array}$ & $\begin{array}{l}\text { - International Posit } \\
\text { Association }\end{array}$ & \\
\hline
\end{tabular}


Reviews of positive psychology literature in specific regions and cultures (e.g., South Africa: Coetzee \& Viviers, 2007; Africa: Eloff, Achoui, Chireshe, Mutepfa, \& Ofovwe, 2008; the Middle East and North Africa: Rao, Donaldson, \& Doiron, 2015; non-Western cultures: Selin \& Davey, 2012; Latin America: Solano, 2014) have attempted to capture the scope and influence of positive psychology within these regions. However, these reviews, while commendable, tell us little about the differences and similarities in positive psychology research across regions in terms of prevalence, methodologies, and research topics. Some broad reviews and volumes have hinted at the growing research across geographic boundaries, but it was beyond their scope to capture the nuances across regions, and therefore, their analysis did not highlight the contributions of regional voices and contextual nuances (Donaldson et al., 2015; Rusk \& Waters, 2013; Sheldon, Kashdan, \& Steger, 2011). Consequently, while previous reviews have made important contributions, they do not illustrate and consolidate the scholarship on an international scale. The current review attempts to address this gap.

Is positive psychology an elite Western phenomenon? Despite its popularity and widespread interest, positive psychology has been criticized for pandering to hegemonic voices and lacking sensitivity to real issues. Critics and theorists point out that the strong North American influence on positive psychology has resulted in placing the individual as the primary focus of research, to the exclusion of historical, cultural, political, and societal contexts (Becker \& Marecek, 2008; Christopher \& Hickinbottom, 2008). Therefore, there has been a need to decenter Western, particularly, North American positive psychology, and make visible contributions across the world. Indeed, in addition to the International Positive Psychology Association (IPPA) that serves a global audience, there are actively engaged scholars and practitioners fueling positive psychology through regional associations (See Table 1 above). The current review will shed light on these regional contributions across the world by examining research trends on a global scale.

\section{Method}

This review examines the prevalence, characteristics, and research topics of the extant empirical research published in positive psychology since the inception of the field in 1998, to 2014. This review builds on and extends a now well-established archive in the field that has been employed in other reviews (e.g., Ackerman, Warren, \& Donaldson, 2017; Donaldson \& Ko, 2010; Donaldson et al., 2015; Rao \& Donaldson, 2015; Rao et al., 2015). This archive consists of 1,628 peer-reviewed English-language articles that include theory, research, reviews, and critiques that identify with positive psychology, published between 1998 and 2014. As described in those reviews, the archive consists of peer-reviewed English-language journal articles gathered by using the search term positive psychology (in quotation marks, with no Boolean operators, searching the full text of the articles) in five electronic research databases: Academic Search ${ }^{\mathrm{TM}}$ Premier, Business Source Premier $^{\circledR}$, ERIC $^{\circledR}$, PsycINFO $^{\circledR}$, and PsycARTICLES ${ }^{\circledR}$.

Similar to the past reviews, we acknowledge that there may be a considerable number of articles published in various languages that have made significant contributions to the field. However, it was beyond the scope and ability of the research team to access and analyze a comprehensive set of articles that were written in languages other than English. Therefore, this archive has been restricted to English-language articles. We also acknowledge the risk of losing valuable research in the field by only reviewing articles that use positive psychology as a term in their full text. However, the epistemological underpinning for this search-term choice (i.e., "positive psychology") was to minimize our own bias in labeling others' articles as positive psychology and to use an objective, albeit restrictive, criterion. Therefore, we maintain this 
explicit criterion used in previous reviews and limit the analysis to literature that explicitly identified with the field of positive psychology.

\subsection{Screening and coding}

The current review focuses on the empirical contributions relevant to the international landscape of positive psychology. Given the importance of geography for this study, a key dilemma that arose was whether to use geographical locations of empirical study samples or locations of author affiliations to determine the location associated with the articles. Location of author affiliation was less practical for two reasons: 1) some authors indicated multiple institutional affiliations, sometimes in different countries; 2) some authors conducted research outside the country of their institutional affiliation. Thus, it was decided that the sample location would serve as a concrete indicator of the region and country in which the research took place.

As a consequence, this limited the review to the examination of empirical articles that clearly reported sample locations. Consequently, the archive of 1,628 articles was screened to eliminate non-empirical articles $(k=656)$. In order to facilitate an analysis by geographical location, articles that did not report a sample location were also screened out $(k=109)$ to create a dataset $(k=863$; henceforth referred to as such; see Figure 1).

Figure 1. Results of literature search (based on PRISMA standards, Moher, Liberati, Tetzlaff, \& Altman, 2009)

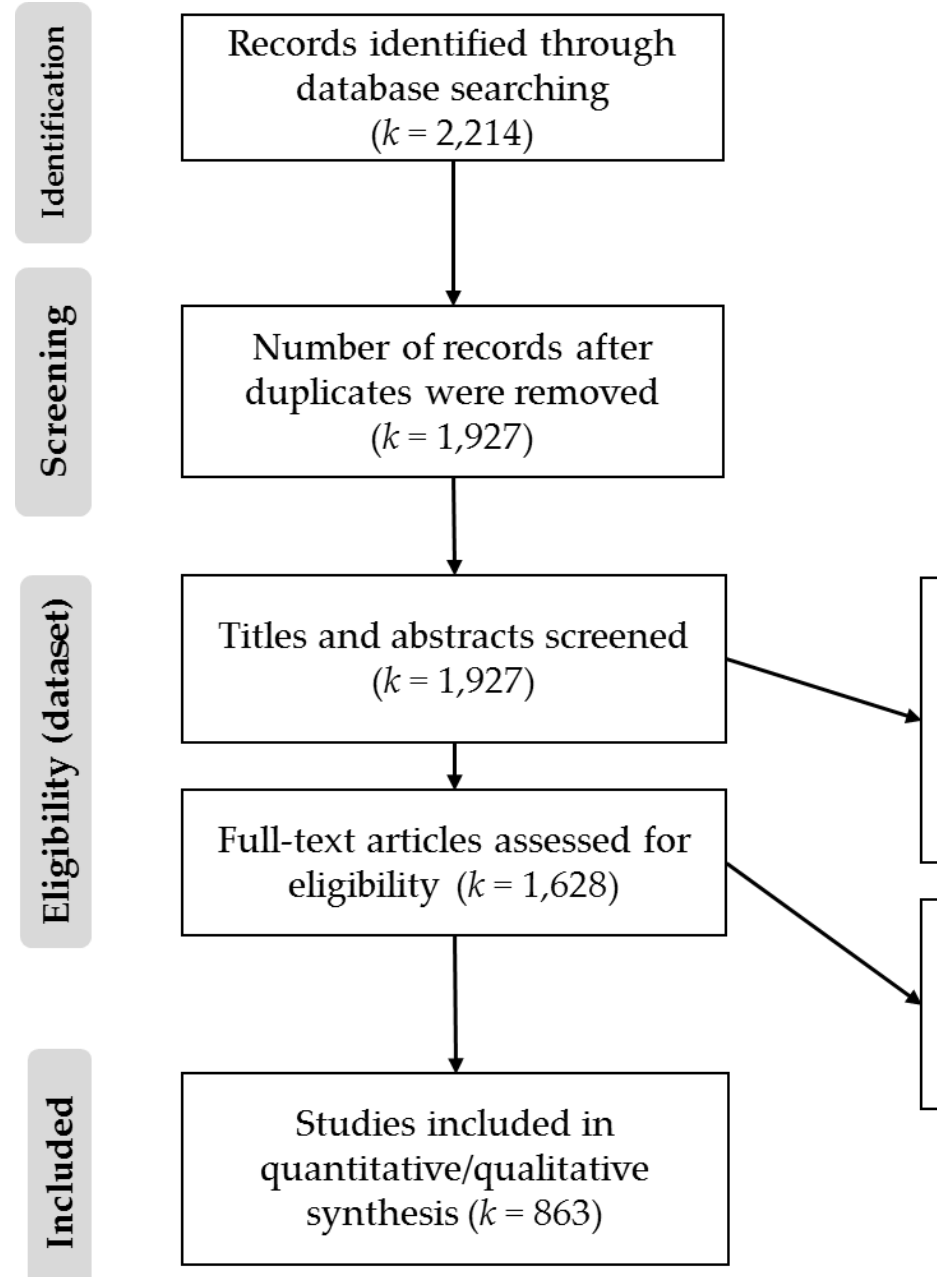

Records excluded $(k=299)^{\mathrm{a}}$

Not peer-reviewed: $k=13$

Not English: $k=33$

Not research/theory: $k=174$

Not positive psychology: $k=152$

Full-text articles excluded, with reasons $(k=765)$

Non-empirical: $k=656$

No sample location: $k=109$

Note: aThe numbers in "Records excluded" do not add up to 299 because these categories are not mutually exclusive. 
After screening, each empirical article was coded to capture prevalence, characteristics and research topics. To determine prevalence, the location of the sample, including continent (i.e., Europe, the Americas, Africa, Asia, and Oceania), region (e.g., Northern Europe), and country were coded. The U.S. was separately coded from the rest of the Americas, as the U.S. had a disproportionately large number of articles, which skewed the analyses when included. Since the positive psychology movement originated in the U.S. (Gable \& Haidt, 2005), it is not surprising that there has been considerable research published therein (see Figure 2), particularly in the first 17 years (from 1998 to 2014) of the movement.

Figure 2. The number of articles published outside the U.S. versus in the U.S. by year

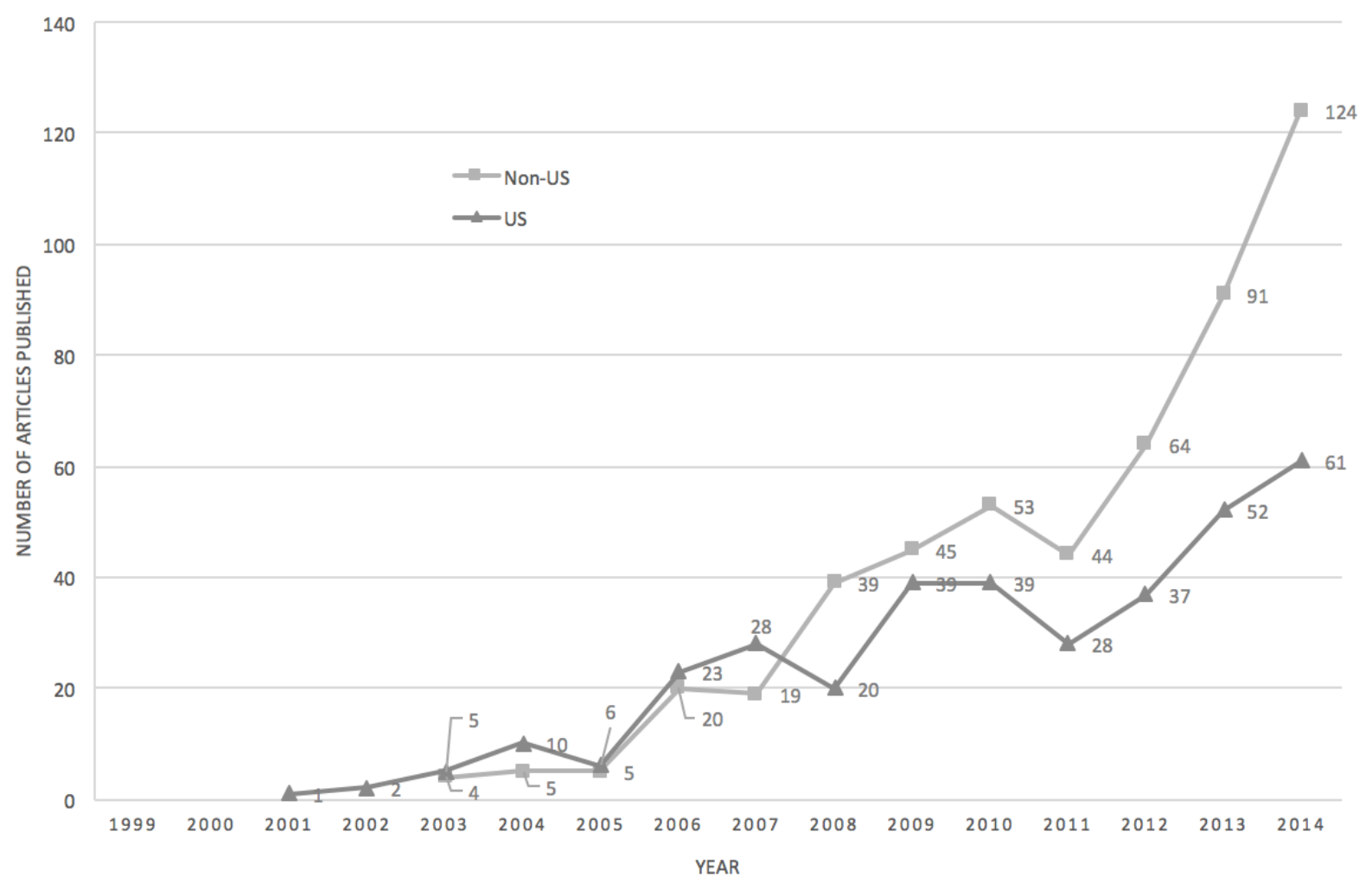

For the analysis of characteristics, we coded methodology, research design, and variables of interest. Five domains of methodology and research design were coded: 1) research methods, including qualitative, quantitative, or mixed methods; 2) level of analysis, including individual, dyad, group, organization, nation, activity/event, or multi-level; 3) study design, including correlational, experimental, or quasi-experimental; 4) study type, including cross-sectional or longitudinal; 5) measurement, including the article's purpose as scale development, scale validation, or both.

Next, articles were coded for key constructs, i.e., predictors, outcomes, and mechanisms, with an eye to emergent topics examined in local contexts. Further, each article was coded for whether it took a positive, deficit, or a combination of both perspectives. In their review, Rao and colleagues (2015) found two main motivations that tend to inspire and guide the direction of positive psychology research. The "positive" perspective refers to an abundance-based approach that focuses on topics related to optimal functioning, wellbeing, and quality of life. Articles that take a "deficit" perspective tend to introduce inherently positive constructs such as hope and benefit-finding as mechanisms and interventions to combat physical or psychological disorders, engage in a redemptive narrative, or help individuals cope with adversity (e.g., conducting self- 
compassion and optimism exercises for the benefit of depressed individuals (Shapira \& Mongrain, 2010)). While most articles took one perspective or the other, some used a combination of perspectives to investigate the impact of positive constructs on a range of outcomes (e.g., wellbeing as well as depression as intervention outcomes). These articles were coded as "neutral."

Finally, the influence of positive psychology research across the world was examined using a qualitative analysis of the articles in the dataset. The main themes were drawn and interpretations are discussed.

\section{Results}

\subsection{Prevalence}

Of all the positive psychology articles in the dataset that reported sample locations, $41 \%(k=350$ articles) were from the U.S. Therefore, in some analyses in this review, the U.S. is used as a reference point, and at other times it is excluded from the analysis to facilitate comparison and fine-grained examination of research conducted in regions outside of the U.S. Accordingly, research conducted outside of the U.S. may be referred to as "non-U.S." research hereafter.

The number of articles published outside of the U.S. encompassed $52 \%$ of the articles in this dataset, including those from five continents, namely, Europe $(k=209)$, Asia $(k=114)$, the Americas $(k=52)$, Oceania $(k=46)$, and Africa $(k=25)$. The remaining $7 \%(k=67)$ was comprised of multi-national articles. Although these numbers are smaller than the articles produced in the U.S., the percentage of research taking place outside of the U.S. tends to increase every year. (See Figure 2; though there are a few dips in the line graphs, the number of articles published generally increases every year.) Examination of the dataset revealed that empirical research was produced in 62 countries other than the U.S., and the top locations were the United Kingdom ( $k$ =78), Canada $(k=57)$, and Australia $(k=55)$. China $(k=31)$ was ranked fifth and was the top country in Asia, and South Africa $(k=25)$ was ranked seventh and was the top country in Africa (see Table 2 below).

While this review shows the growth of positive psychology research around the world, there is also evidence that some regions and countries tend to be hubs within a continent. For example, $79 \%$ of the positive psychology articles using samples from Africa were from South Africa. In the Americas, apart from the U.S., 85\% of the articles were published in North America (e.g., Canada), compared with only $15 \%$ in South and Central America. Europe and Asia showed similar trends. In Europe, countries in the Northern Europe region (e.g., the U.K., Ireland, Norway, Sweden, Denmark, the Netherlands, and Finland) published $49 \%$ of the entire publications from the continent, while the remaining 51\% were spread between Southern Europe, Western Europe, and Eastern Europe. In Asia, countries in the East Asia region (e.g., China, Hong Kong, Japan, South Korea, and Taiwan) held 52\% of the Asian sample locations within the dataset, while the remaining $48 \%$ were spread between the Middle East, South Asia, and Southeast Asia.

Interest in positive psychology research has been spreading in new regions and countries. In the dataset, 24 countries were represented only once by participant samples (e.g., Kenya, Ukraine, Thailand), and 14 out of these 24 were included only in multinational studies as a comparative research site. 
Table 2. Number of publications by country

\begin{tabular}{|c|c|c|}
\hline Country & Region & $\begin{array}{c}\text { Number of } \\
\text { Publications }\end{array}$ \\
\hline UK & Northern Europe & 78 \\
\hline Canada & Northern America & 57 \\
\hline Australia & Oceania & 55 \\
\hline Germany & Western Europe & 36 \\
\hline China & East Asia & 31 \\
\hline Spain & Southern Europe & 25 \\
\hline Israel & Middle East/North Africa & 25 \\
\hline South Africa & South Africa & 25 \\
\hline Netherlands & Northern Europe & 23 \\
\hline Switzerland & Western Europe & 20 \\
\hline Italy & Southern Europe & 16 \\
\hline India & South Asia & 14 \\
\hline Sweden & Northern Europe & 13 \\
\hline Japan, Taiwan & East Asia & 11 \\
\hline Norway & Northern Europe & 11 \\
\hline Belgium & Western Europe & 9 \\
\hline Hong Kong & East Asia & 8 \\
\hline South Korea & East Asia & 8 \\
\hline Turkey & Eastern Europe & 7 \\
\hline Iran & Middle East/North Africa & 7 \\
\hline New Zealand & Oceania & 6 \\
\hline Singapore & Southeast Asia & 6 \\
\hline Russia & Eastern Europe & 5 \\
\hline Denmark & Northern Europe & 5 \\
\hline Brazil & South \& Central America & 5 \\
\hline Romania & Eastern Europe & 4 \\
\hline Ireland & Northern Europe & 4 \\
\hline Austria & Western Europe & 4 \\
\hline Croatia & Eastern Europe & 3 \\
\hline Finland & Northern Europe & 3 \\
\hline France & Western Europe & 3 \\
\hline Poland & Eastern Europe & 2 \\
\hline Argentina & South \& Central America & 2 \\
\hline Indonesia. Malaysia & Southeast Asia & 2 \\
\hline Portugal, Greece & Southern Europe & 2 \\
\hline Cameroon, Nigeria & Central \& Western Africa & 1 \\
\hline Kenya, Malawi, Tanzania, Uganda, Zimbabwe & East Africa & 1 \\
\hline Hungary, Kosovo, Serbia & Eastern Europe & 1 \\
\hline Kuwait, Afghanistan, Algeria, Jordan, Egypt & Middle East/North Africa & 1 \\
\hline Northern Ireland & Northern Europe & 1 \\
\hline El Salvador, Nicaragua, Bolivia & South \& Central America & 1 \\
\hline Lesotho & South Africa & 1 \\
\hline Pakistan & South Asia & 1 \\
\hline Thailand & Southeast Asia & 1 \\
\hline Malta & Southern Europe & 1 \\
\hline
\end{tabular}




\subsection{Characteristics}

To understand the characteristics of positive psychology across regions, we coded the methodologies used in the articles by continents (see Table 3). We analyzed various aspects of methodologies, including research method, level of analysis, study design, and scale research. Table 3 summarizes the use of methods and design of research in each continent. The results largely confirmed the trend of conducting much quantitative, individual-level, correlational and cross-sectional research but also show the effort of using various other methods and designs in each region.

Table 3. Methodologies by continent (\%)

\begin{tabular}{|c|c|c|c|c|c|c|c|c|}
\hline & $\begin{array}{c}\text { Africa } \\
n=25\end{array}$ & $\begin{array}{c}\text { Americas } \\
n=52\end{array}$ & $\begin{array}{c}\text { Asia } \\
n=114\end{array}$ & $\begin{array}{c}\text { Europe } \\
n=209\end{array}$ & $\begin{array}{c}\text { Oceania } \\
n=46\end{array}$ & $\begin{array}{c}\text { US } \\
n=350\end{array}$ & $\begin{array}{c}\text { Multi } \\
n=67\end{array}$ & Total (\%) \\
\hline \multicolumn{9}{|l|}{ Research Method } \\
\hline Quantitative & $15\left(60^{a}\right)$ & $34(65)$ & $96(84)$ & $171(81)$ & $28(60)$ & $287(82)$ & $49(73)$ & $680\left(78.8^{b}\right)$ \\
\hline Qualitative & $7(28)$ & $8(15)$ & $8(7)$ & $22(11)$ & $9(20)$ & $26(7)$ & $10(15)$ & $90(10.4)$ \\
\hline Mixed & $3(12)$ & $9(17)$ & $9(8)$ & $16(8)$ & $9(20)$ & $34(10)$ & $8(12)$ & $88(10.2)$ \\
\hline Missing & - & $1(2)$ & $1(1)$ & - & - & $3(1)$ & - & $5(0.6)$ \\
\hline \multicolumn{9}{|l|}{ Level of Analysis } \\
\hline Individual & $21(84)$ & $44(85)$ & $92(81)$ & $175(84)$ & $37(80)$ & $313(89)$ & $48(72)$ & $730(84.6)$ \\
\hline Dyad & 0 & $1(2)$ & $4(4)$ & $3(1)$ & $1(2)$ & $7(2)$ & $2(3)$ & $18(2.1)$ \\
\hline Group & $1(4)$ & $3(6)$ & $11(10)$ & $17(8)$ & $4(9)$ & $13(4)$ & $2(3)$ & $51(5.9)$ \\
\hline Organization & - & $1(2)$ & - & $3(1)$ & - & $5(1)$ & - & $9(1)$ \\
\hline Nation & $1(4)$ & - & - & - & - & $1(0)$ & $8(12)$ & $10(1.2)$ \\
\hline Activity/Event & - & $1(2)$ & $1(1)$ & $5(1)$ & $1(2)$ & $4(1)$ & $2(3)$ & $14(1.6)$ \\
\hline Multi-level & $2(8)$ & - & $5(5)$ & $3(1)$ & $3(7)$ & $4(1)$ & $4(6)$ & $21(2.4)$ \\
\hline Missing & - & $2(4)$ & $1(1)$ & $3(1)$ & - & $3(1)$ & $1(3)$ & $10(1.2)$ \\
\hline \multicolumn{9}{|l|}{ Study Design 1} \\
\hline Correlational & $19(76)$ & $35(67)$ & $84(74)$ & $157(75)$ & $24(52)$ & $253(72)$ & $55(82)$ & $627(72.7)$ \\
\hline Experimental & $1(4)$ & $4(7)$ & $12(11)$ & $28(13)$ & $13(28)$ & 44 (13) & $2(3)$ & $104(12.1)$ \\
\hline $\begin{array}{l}\text { Quasi- } \\
\text { Experimental }\end{array}$ & $2(8)$ & $6(12)$ & $13(11)$ & $17(8)$ & $4(9)$ & $38(11)$ & $5(7)$ & $85(9.8)$ \\
\hline Missing & $3(12)$ & $7(13)$ & $5(4)$ & $7(3)$ & $5(11)$ & $15(4)$ & $5(7)$ & $47(5.4)$ \\
\hline \multicolumn{9}{|l|}{ Study Design 2} \\
\hline Cross-Sectional & $20(80)$ & $34(65)$ & $90(79)$ & $152(73)$ & $28(61)$ & $260(74)$ & $62(93)$ & 646 (74.9) \\
\hline Longitudinal & $1(4)$ & $9(17)$ & $15(13)$ & $40(19)$ & $10(22)$ & $55(16)$ & $2(3)$ & $132(15.3)$ \\
\hline Others & $2(8)$ & $4(8)$ & $8(7)$ & $16(8)$ & $6(13)$ & $28(8)$ & 0 & $64(7.4)$ \\
\hline Missing & $2(8)$ & $5(10)$ & $1(1)$ & $1(0)$ & $2(4)$ & $7(2)$ & $3(4)$ & $21(2.4)$ \\
\hline \multicolumn{9}{|l|}{ Scale Research } \\
\hline $\begin{array}{l}\text { Scale } \\
\text { Development }\end{array}$ & $1(4)$ & $3(6)$ & 0 & $4(2)$ & $2(4)$ & $8(2)$ & $2(3)$ & $20(2.3)$ \\
\hline Scale Validation & $3(12)$ & $3(6)$ & $13(11)$ & $6(3)$ & $1(2)$ & $15(4)$ & $7(10)$ & $48(5.6)$ \\
\hline Both & $1(4)$ & $1(2)$ & $3(3)$ & $6(3)$ & 0 & $9(3)$ & $4(6)$ & $24(2.8)$ \\
\hline Neither & $20(80)$ & $43(83)$ & $97(85)$ & $191(91)$ & $42(91)$ & $315(90)$ & $52(90)$ & $760(88.1)$ \\
\hline Missing & - & $2(4)$ & $1(1)$ & $2(1)$ & $1(2)$ & $3(1)$ & $2(3)$ & $11(1.3)$ \\
\hline
\end{tabular}

Note: a Percentage of number of each method out of total number of articles within the continent. Percentages may not add up to 100 within each continent, as we rounded up .5 or above for individual scores; ${ }^{b}$ percentage of number of each method out of total number of articles $(k=863)$. 


\subsection{Topics}

We analyzed the topics of research as another characteristic of positive psychology research in regions. The independent and dependent variables of articles were coded and analyzed to identify topics and constructs studied across continents. Themes that emerged across regions and continents were used to create extensive lists of topics studied as predictors or outcomes, and their frequency was calculated. Popular themes and topics unique to each continent were identified.

Predictors. Topic analysis across continents indicated that gratitude $(k=35)$ and personality variables (e.g., Big Five; $k=15$ ) were the most commonly studied predictors among all regions (see Table 4 below).

In Asian studies, emotional intelligence $(k=3)$, stability and balance $(k=2)$, and savoring $(k=2)$ were the main predictors of interest beyond the variables commonly used in positive psychology research across regions. In African studies, violence and trauma $(k=3)$ were most commonly studied. In the Americas, compassion $(k=2)$ and positive behavior support $(k=2)$ were commonly studied, while in Europe engagement $(k=5)$ was. In Oceania, coaching interventions $(k=7)$ were a commonly studied predictor, and in the U.S., leisure $(k=9)$, courage $(k=8)$, and autonomy $(k=6)$ were among the unique top ten predictors beyond the variables commonly studied in positive psychology in general.

Outcomes. The dependent variables again showed some unique patterns in each region. Predictably, the dependent variables found in common across all regions are among the most commonly investigated topics in positive psychology overall (Donaldson et al., 2015; see Table 4 above), including wellbeing $(k=149)$, life satisfaction $(k=91)$, positive/negative affect $(k=87)$, happiness $(k=60)$, and resilience $(k=28)$. In research from Asia, social acceptance $(k=2)$, self-efficacy $(k=2)$, and post-traumatic stress $(k=2)$ were unique among the top dependent variables. In Africa, coping and recovery $(k=2)$ were commonly studied, while in Europe, anxiety $(k=11)$ and the concept of flow (Csikszentmihalyi, 1990; $k=5$ ) were common outcomes of interest. In the Americas, values ( $k$ $=2$ ) and humor $(k=2)$ were commonly studied outcomes, in Oceania, positive youth development $(k$ $=6$ ) and positive relationships $(k=2)$ were commonly studied, and in the U.S., achievement $(k=8)$, attenuating of risk behaviors $(k=7)$, purpose $(k=6)$, and altruism $(k=5)$ were relatively common outcome variables.

Positive or Deficit Perspective. Overall, $46 \%$ of the articles in the dataset $(k=397)$ took a positive perspective, $29 \%(k=251)$ took a deficit perspective, and $25 \%$ used both positive and deficit perspectives $(k=215)$. The highest percentages of a deficit approach $(40 \%$ of articles $)$ were from Africa and the Americas ( $k=10, k=21$ respectively). The highest percentages of positive approaches were from Oceania $(56 \% ; k=26)$ and multinational studies $(57 \%, k=38)$. See Table 5 below for exact frequencies. 
Table 4. Frequencies of predictors and outcomes across continents/regions

\begin{tabular}{|c|c|c|}
\hline & Predictors & Outcomes \\
\hline \multirow{7}{*}{ Common } & Gratitude (35) & Wellbeing (149) \\
\hline & Personality (15) & Life Satisfaction (91) \\
\hline & & Positive or negative affect (87) \\
\hline & & Happiness $(60)$ \\
\hline & & Depression (48) \\
\hline & & Health (39) \\
\hline & & Resilience (28) \\
\hline \multirow{9}{*}{ Asia } & Emotional intelligence (3) & Employability (2) \\
\hline & Neuroticism (3) & Social acceptance (2) \\
\hline & Resilience (3) & Post-traumatic stress (2) \\
\hline & Positive external-concept (2) & Self-efficacy (2) \\
\hline & Savoring (2) & \\
\hline & Self-concept (2) & \\
\hline & Stability/Balance (2) & \\
\hline & Trust (2) & \\
\hline & Attributional style (2) & \\
\hline Africa & Violence/Trauma (3) & Coping/Recovery (2) \\
\hline \multirow{5}{*}{ Americas } & Motivation (3) & Moral excellence (2) \\
\hline & Compassion (2) & Self-acceptance (2) \\
\hline & Psychological resources (2) & Values (2) \\
\hline & Positive behavior support (2) & Humor (2) \\
\hline & & Turnover (2) \\
\hline \multirow{2}{*}{ Europe } & Engagement (5) & Anxiety (11) \\
\hline & & Flow (5) \\
\hline \multirow{5}{*}{ Oceania } & Coaching (7) & Positive youth development (6) \\
\hline & Calling (2) & Floundering (2) \\
\hline & & Parenting style (2) \\
\hline & & Positive relationships (2) \\
\hline & & Flourishing (2) \\
\hline \multirow{3}{*}{ Multi-national } & Power/Powerlessness (3) & Approach/avoidance (3) \\
\hline & Eudaimonic and hedonic dispositions (2) & Emotional disclosure (3) \\
\hline & & Meditation/mindfulness (3) \\
\hline \multirow{10}{*}{ US } & Leisure (9) & Achievement (8) \\
\hline & Courage (8) & Organizational commitment (7) \\
\hline & Humility (7) & Attenuating risk behavior (7) \\
\hline & Attachment (7) & Courage (6) \\
\hline & Self-regulation (7) & Purpose (6) \\
\hline & Autonomy (6) & Altruism (5) \\
\hline & Post-traumatic growth (5) & Creativity (5) \\
\hline & & Effort (5) \\
\hline & & Adjustment (5) \\
\hline & & Prosocial activities (5) \\
\hline
\end{tabular}


Table 5. Frequencies of positive, neutral, and deficit approaches (\%)

\begin{tabular}{lcccccccc}
\hline & $\begin{array}{c}\text { Africa } \\
(\boldsymbol{k}=\mathbf{2 5 )}\end{array}$ & $\begin{array}{c}\text { Americas } \\
(\boldsymbol{k}=\mathbf{5 2})\end{array}$ & $\begin{array}{c}\text { Asia } \\
(\boldsymbol{k}=\mathbf{1 1 4})\end{array}$ & $\begin{array}{c}\text { Europe } \\
(\boldsymbol{k}=\mathbf{2 0 9})\end{array}$ & $\begin{array}{c}\text { Oceania } \\
(\boldsymbol{k}=\mathbf{4 6 )}\end{array}$ & $\begin{array}{c}\text { US } \\
(\boldsymbol{k}=\mathbf{3 5 0 )}\end{array}$ & $\begin{array}{c}\text { Multi } \\
(\boldsymbol{k}=\mathbf{6 7 )}\end{array}$ & Total (\%) \\
\hline Positive & $10(40)$ & $18(35)$ & $55(48)$ & $88(42)$ & $26(57)$ & $162(46)$ & $38(57)$ & $397(46)$ \\
Neutral & $4(16)$ & $13(25)$ & $22(19)$ & $52(25)$ & $9(20)$ & $97(28)$ & $17(25)$ & $215(24.9)$ \\
Deficit & $10(40)$ & $21(40)$ & $37(32)$ & $69(33)$ & $11(24)$ & $91(26)$ & $12(18)$ & $251(29.1)$ \\
\hline
\end{tabular}

Indigenous Issues. The results from the analysis of indigenous issues demonstrated that some positive psychologists are addressing pertinent and socially relevant local events. This shows the potential of positive psychology to address the pressing events that affect people's lives all over the world, although the actual number of articles including local topics is small in this analysis ( $k=44$; see Table 6 for frequency of topics).

Table 6. Frequencies of local topics studied

\begin{tabular}{ll}
\hline & Post-traumatic stress (Israel: 2) \\
& Burnout (China: 1) \\
& Migrant workers (China: 1) \\
& Economic transition (China: 1) \\
& Earthquake survivors (Indonesia: 1) \\
& Children exposed to war (Afghanistan: 1) \\
& Cumulative adversity (Israel: 1) \\
& Missile attacks (Israel: 1) \\
& Mystical experiences of Muslims (1) \\
& Cultural groups in South Africa (4) \\
& HIV/AIDS (South Africa: 2) \\
Africa & African-centered coping (South Africa: 1) \\
\hline \multirow{2}{*}{ Americas } & Trash pickers (Nicaragua: 1) \\
& First Nations cultural trauma (Canada: 1) \\
\hline \multirow{2}{*}{ Europe } & Terrorism (Spain: 2) \\
& HIV/AIDS (Russia: 1) \\
& Football supporters (England: 1) \\
\hline Oceania & Indigenous students (Australia: 1) \\
\hline Multi-National & - \\
\hline & Minority issues of races (9) \\
US & September 9/11 (4) \\
& Hurricane Katrina (3) \\
& College campus shooting (1) \\
Low-income Housing in NYC (1) & No Child Left Behind (1) \\
& War refugees (1) \\
\hline
\end{tabular}

For example, in Asia, some research in the Middle East had focused on trauma and posttraumatic stress in response to chronic violence. Some studies in China had examined the response of migrant workers and their children to the large economic transition that has taken place over the past decade, as well as the associated stigma. In the Americas, study samples included trash pickers in Nicaragua and Aboriginal students in Canada. In Europe, research 
investigated the impact of terrorism in Spain. In South Africa, a commonly studied topic of research involved the comparison of various ethnic groups and tribes that live together in the country. Studies in the U.S. included research on race and ethnicity issues (e.g., African Americans, immigrants) as well as the impact of the terrorist attack on September 11, 2001 and Hurricane Katrina in 2005.

\subsection{Influences}

We closely examined articles that demonstrated how positive psychology research is influencing the lives of individuals, groups, and nations. Accordingly, the findings from our qualitative review highlighted main themes that show how positive psychology research is making influential contributions and shifting the discourse across the world.

Resilience after traumatic events. Positive psychology has inspired research on the study of unexpected positive outcomes that emerge in the aftermath of man-made and natural disasters. One such area of research emerging in many locations around the world is the examination of resilience and benefit-finding after large-scale traumatic events such as terrorist attacks and earthquakes. Weeks after a terrorist attack in Spain, Vázquez and Hervás (2010) found that citizens were finding potential benefits (e.g., learning from the experience, meaning in life) in the aftermath of the attack, as well as experiencing positive reactions such as solidarity and a feeling of belonging to the nation. In a related vein, Hobfoll and his colleagues $(2009 ; 2012)$ have focused on understanding how one can cultivate resilience and the ability to stay engaged and vigorous in life while facing the constant threat of trauma and violence on the West Bank and the Gaza Strip.

Another area of contribution of positive psychology research is the development of new constructs, and contextualized investigation of established constructs to capture how human strengths can provide a buffer against the effects of adversity. In a study of survivors of the 2009 earthquake in Indonesia, Lies, Mellor, and Hong (2014) found that hardiness and gratitude were negatively related to global distress and posttraumatic stress symptoms five and eight months after the earthquake, respectively.

Resilience after disease or injury. Experiencing a serious disease or a catastrophic injury is often traumatic for individuals and their families. Positive psychology research in this area has investigated strengths-based interventions and practices to buffer the impact, increase resilience, and actively cope with these conditions. The review by Casellas-Grau, Font, and Vives (2014) of 16 studies on positive psychology interventions for breast cancer patients demonstrated that well-designed interventions can help individuals with making meaning and sense of their condition, foster hope, and cultivate positive emotions. Similarly, there is a growing body of research on interventions fostering posttraumatic growth and benefit-finding with cancer patients and individuals with other traumatic health problems all over the world, including in China, Romania, and the UK (Ho, Chan, \& Ho, 2004; Kállay, 2008; Oaksford, Frude, \& Cuddihy, 2005).

Another key contribution of positive psychology research is on understanding the complexities of people living with HIV and AIDS, and developing interventions to alleviate their problems. Pecoraro et al. (2014) found that HIV patients facing stigma and discrimination were more likely to stay in treatment if desire to live, social support, spirituality, and positive thinking were present in their lives. In another instance, Wood, Theron, and Mayaba (2012) found that reading culturally relevant stories to children who had been orphaned by AIDS led to increased resilience. 
Positive experiences of marginalized populations. A small but promising body of positive psychology research is on recognizing positive emotions and strengths in marginalized populations. In dominant scholarly research and popular literature, marginalized populations have often been deemed as unhealthy, depressed, and frustrated (e.g., Choi, Miller, \& Wilbur, 2009). However, contrary to popular notions, initial evidence suggests that marginalization from society itself does not necessarily predict negative affect and depression. Vázquez (2013) found that an impoverished and stigmatized population (i.e., trash pickers) also experienced high levels of happiness and optimism. According to their findings, these individuals tended to find pathways to happiness through familial relationships and having time to participate in relatively inexpensive leisure activities like reading, rather than through having a high income. This aligns with Biswas-Diener and Diener's (2006) findings on experience of happiness among slum dwellers in India.

Moreover, the positive psychological perspective has served as a unifying mechanism to organize and combine interventions for marginalized populations. Brendtro, Brokenleg, and Van Bockern (2005) suggested the Circle of Courage as a theme for interventions that promote significance, competence, power, and virtue among native people suffering from intergenerational cultural traumas. They stressed the importance of a strengths-based approach rather than deficit-focused approach to youth development and created a new space for development and implementation of positive-oriented programs and policies.

Indicators of happiness across cultures. Another way that positive psychologists are making an impact is through cross-cultural research that demonstrates the similarities and differences in indicators of happiness and wellbeing around the world. For example, Delle Fave, Brdar, Friere, Vella-Brodrick, and Wissing (2011) investigated the components of happiness across seven countries. The authors found that happiness was commonly defined as psychological balance or harmony and that social and familial relationships are the largest predictor of happiness. Brannan, Biswas-Diener, Mohr, Mortazavi, and Stein (2013) looked at the relationship between social support and wellbeing in Iran, Jordan, and the U.S. and found that family support predicted wellbeing in all three countries, while friend support was predictive only in the U.S. and Jordan. These findings highlight the nuances in the role of interaction between social relationships and culture on wellbeing. In other words, while social support is a common predictor of happiness and wellbeing across nations, there are cultural differences in the type and nature of social support necessary for greater wellbeing.

In another instance, Kormi-Nouri, Farahani, and Trost (2013) observed different relationships between affect and wellbeing in Sweden and Iran. As increased positive affect led to increased wellbeing among Swedish participants, a balance of positive and negative emotions led to higher wellbeing for the Iranian participants. This shows that while people around the world may have some similar predictors of happiness, there are often cultural differences in how these indicators operate in predicting happiness and wellbeing.

Balance between positive and negative. Positive psychology is often misunderstood as being concerned only with rosy aspects, while neglecting harsh realities of life (e.g., Fineman, 2006). Early proponents of positive psychology have insisted that the purpose of positive psychology is to balance positive and negative perspectives in the psychological sciences, and our review supports this. Positive psychology research has made important contributions in finding ways to strike a balance between the inherently positive and negative aspects of human experience and explain both. For example, Vallerand et al. (2008) showed that football supporters may experience both positive and negative consequences from their acts of team-support. Previous research encountered a "paradox," where supporters of sports teams are related to both positive 
(e.g., psychological health) and negative (e.g., aggression) outcomes. Vallerand et al. (2008) adopted the Dualistic Model of Passion (Vallerand et al., 2003) and explained the paradox, such that individuals' passion types (i.e., harmonious or obsessive) predicted positive and negative consequences. This research presents a case where positive psychology not only argues for positive aspects of life, but equally encompasses both positive and negative aspects of a phenomenon in a single model. (For another example, see Keyes's (2003) Model of Languishing and Flourishing.)

\section{Discussion}

The purpose of this review was to understand the overall landscape of positive psychology research that has emerged in various regions across the world in the initial 17 years of the field and to examine the validity of some of the critiques of positive psychology. Thus, the review examined the prevalence, characteristics, and influence of empirical research in positive psychology across the world.

\subsection{Global presence}

Positive psychology was found to have a large and growing global presence and visibility. The analysis reveals that positive psychology is entering and making important contributions in the scholarly conversations and debates across a range of important societal issues around the world. Further, positive psychology is no longer a United States and Western phenomenon as much as a psychological science in general. Past reviews of research in psychological science have criticized that peer-reviewed psychological research is dominated by the United States and Westernized samples. For instance, Arnett (2008) found that $68 \%$ of samples of studies published in top journals of six sub-disciplines of psychology were from the United States, and $96 \%$ from Westernized countries. In contrast, in the current review, $41 \%$ of the samples in positive psychology studies were from the United States, and 70\% from Westernized countries. Thus, while positive psychology has been criticized for ethnocentrism (Christopher \& Hickinbottom, 2008), this review shows that it fares better than the psychological research included in Arnett (2008).

\subsection{Methodological relevance}

The analysis of methodologies used in the articles in the dataset reveals that the field is dominated by studies using quantitative, correlational, and individual-level analyses. While these tendencies are still observed, geographical analyses by continent indicate that preferences for methodologies show some variations within and across regions, depending on their contexts and regional concerns. For instance, research emerging from Africa has several qualitative studies that may be explained in part due to a strong history of storytelling and the resulting influence on the choice of research methods (e.g., Reitmaier, Bidwell, \& Marsden, 2011). The research published in the U.S. showed a high percentage of individual-level analysis, and in Asia there was a good number of group-level analyses, potentially reflecting the cultural differences in individualism and collectivism (Hofstede, 1984). Finally, compared to other regions, in Oceania, a higher percentage of empirical studies employed mixed methods, longitudinal designs, experimental methods, and multi-level analyses. These are prima facie considered to be more desirable methodological practices in psychology, although the current analysis does not assess quality and rigor of individual studies. Future research should examine the determinants of the use of research methods among scholars. 


\subsection{Conceptual balance}

One of the most noteworthy findings from the analyses of topics and constructs studied was that research in positive psychology not only includes investigation of positive topics but also their interaction with and impact on psychological dysfunction (e.g., depression) and social issues (e.g., terrorism). This growing balance directly addresses one of the common concerns of positive psychology: that the field solely focuses on positivity, neglecting the negative reality of human life and society (Hackman, 2009). Further, cultural, social, and political issues and priorities in the regions influenced which constructs were studied and how this balance was achieved. A research interest in stability in Asian research might reflect the values of religious traditions (e.g., Buddhism, Hinduism), while predictors such as trauma and violence, and outcomes such as coping and recovery in African research point to the historical and political struggles in the region (e.g., civil war, drought, and famine). Similarly, the prevalence of posttraumatic stress and resilience as outcome variables in Asian research may reflect research on managing adversity arising from wars in the Middle East.

\subsection{Global relevance}

Positive psychology scholars have added value to past and established research on posttraumatic stress and recovery through exploration of the human aftermath of large-scale traumatic events (e.g., Vázquez \& Hervás, 2010) and the resilience of individuals who have been affected by disease or injury (e.g., Casellas-Grau et al., 2014). These studies show that evidence-based interventions are being applied to the most pressing issues of our time, such as combating the effects of terrorism and the HIV/AIDS epidemic. The research indicates that happiness and strengths exist in human beings in any circumstance, not exclusively among wealthy, privileged individuals (e.g., Vazquez, 2013). Further, while happiness and wellbeing may be experienced and expressed through different means across populations, positive psychology research and interventions can help understand and improve the quality of life for all, regardless of their current life circumstances (Delle Fave et al., 2011).

\subsection{Strengths, limitations, and future directions}

The purpose of this review was to examine the global landscape of research in positive psychology in its initial years, and, as such, is the first large-scale analysis of its kind. As the articles for this review were extracted from several large electronic databases, it is expected that it provides a fairly reliable estimate of the state of the field. As positive psychology gets close to the end of its second decade of existence, this review provides a summary of the first 17 years of the field across the world and highlights the emergence of what might be termed as the next generation of positive psychology that is increasingly diverse, culturally responsive, contextual, and influential.

However, it is important to view this study in light of its limitations. The current investigation faces the limitations of previous reviews that have used similar methods (Donaldson \& Ko, 2010; Donaldson et al., 2015; Rao \& Donaldson, 2015; Rao et al., 2015). Specifically, it includes only research published in English, and therefore underestimates the breadth and depth of positive psychology's prevalence and impact around the world. Similarly, only research that explicitly identified with or situated itself in relation to positive psychology was included in this analysis. Thus, authors' identification with alternative labels for positive psychology, such as psychofortology in South Africa (Strümpfer, 2005), may have caused an underestimation of the global influence of positive psychology. In addition, the paper does not 
exhaustively cover all topics in positive psychology, and instead focuses on highlighting prominent trends, thereby inadvertently excluding some (e.g., wisdom).

Although the current analytical strategy emphasizes the research participants (i.e., where they are situated) so that it allows for commentary on the psychological phenomena of the people in the region, we acknowledge that using a different criterion (e.g., author location) would have enabled us to conduct other interesting analyses, such as patterns of multinational collaboration in scholarship. Future studies could explore this. Finally, the current study did not account for the impact of articles, which may be reflected in the impact factors of the journals or the number of citations of articles. Weighing the count of articles with a measure of impact may highlight regions that have few articles yet may have high impact on the field.

While the current study focused on presenting an international landscape of the field of positive psychology, future research can delve into some of the trends observed in this study to investigate the "why" and "how" of those trends. Future research can also conduct reviews of the later years of the field to compare and contrast the new trends to these initial years and examine the changes. As a broader suggestion based on our findings, we recommend increased focus on the development of a culturally responsive positive psychology. A key area for growth of the field is the development, measurement, and testing of constructs that are grounded in the social, economic, and political context of the region. Further, we call for increased cross-cultural comparative research that showcases the complex nature and multi-dimensionality of positive constructs and their relevance across cultures and contexts.

\section{Conclusion}

This study summarized the first 17 years of research in the field of positive psychology. While the field is still in nascence, scholars in positive psychology have made important progress across the world, giving rise to some general trends and regional perspectives. We anchored the analyses partially around the early criticisms of the field, which provide guidance for the future of positive psychology as an established field in psychology. Csikszentmihalyi (1993) noted that an individual or system develops and becomes richer through successfully balancing differentiation and integration. Differentiation involves pursuing uniqueness and distinguishing oneself from others, while integration entails unifying with others by creating something beyond oneself. Positive psychology as a field will benefit from this approach by cultivating cultural sensitivity regarding human life in different contexts and integrating a wide range of perspectives and approaches into a unified view.

\section{Acknowledgments}

Special thanks to Maria McManus and Annelise Austill, Claremont Graduate University, and Russell Donaldson, Redlands University, for assistance with coding and database management, and Noah Boyd, Joo Young Lee, and Scott Donaldson, Claremont Graduate University, for their helpful review and edits. A portion of this paper was awarded $3^{\text {rd }}$ place by the American Psychological Association's International Psychology Division (Division 52) at the Western Psychological Association Convention 2016.

\section{Authors}

Heejin Kim

University of California, Irvine

heejin.kim@uci.edu

Kathryn Doiron

Claremont Graduate University 
Meg A. Warren

Claremont Graduate University

Western Washington University

Stewart I. Donaldson

Claremont Graduate University

\section{Publishing Timeline}

Received 30 July 2017

Accepted 5 February 2018

Published 13 July 2018

\section{References}

Ackerman, C., Warren, M. A., \& Donaldson, S. I. (2018). Scaling the heights of positive psychology: A systematic review of measurement. Unpublished Manuscript.

Arnett, J. J. (2008). The neglected 95\%: Why American psychology needs to become less American. American Psychologist, 63, 602-614. https://doi.org/10.1037/0003-066X.63.7.602

Becker, D., \& Marecek, J. (2008). Positive psychology: History in the remaking? Theory \& Psychology, 18, 591-604. https://doi.org/10.1177/0959354308093397

Biswas-Diener, R., \& Diener, E. D. (2006). The subjective well-being of the homeless, and lessons for happiness. Social Indicators Research, 76, 185-205. https://doi.org/10.1007/s11205-005-8671-9

Borsari, B., \& Carey, K. B. (2001). Peer influences on college drinking: A review of the research. Journal of Substance Abuse, 13, 391-424. https://doi.org/10.1016/S0899-3289(01)00098-0

Brannan, D., Biswas-Diener, R., Mohr, C. D., Mortazavi, S., \& Stein, N. (2013). Friends and family: A cross-cultural investigation of social support and subjective well-being among college students. The Journal of Positive Psychology, 8, 65-75. https://doi.org/10.1080/17439760.2012.743573

Brendtro, L., Brokenleg, M., \& Van Bockern, S. (2005). The circle of courage and positive psychology. Reclaiming Children and Youth, 14, 130-136.

Casellas-Grau, A., Font, A., \& Vives, J. (2014). Positive psychology interventions in breast cancer. A systematic review. Psycho-Oncology, 23, 9-19. https://doi.org/10.1002/pon.3353

Choi, J., Miller, A., \& Wilbur, J. (2009). Acculturation and depressive symptoms in Korean immigrant women. Journal of Immigrant and Minority Health, 11, 13-19. https://doi.org/10.1007/s10903-007-9080-8

Christopher, J. C., \& Hickinbottom, S. (2008). Positive psychology, ethnocentrism, and the disguised ideology of individualism. Theory \& Psychology, 18, 563-589. https://doi.org/10.1177/0959354308093396

Coetzee, S., \& Viviers, R. (2007). An overview of research on positive psychology in South Africa. South African Journal of Psychology, 37, 470-490. https://doi.org/10.1177/008124630703700307

Csikszentmihalyi, M. (1990). Flow: The psychology of optimal performance. New York, NY: Cambridge University Press.

Csikszentmihalyi, M. (1993). Evolving self. New York, NY: HarperCollins.

Dahlsgaard, K., Peterson, C., \& Seligman, M. P. (2005). Shared virtue: The convergence of valued human strengths across culture and history. Review of General Psychology, 9, 203-213. https://doi.org/10.1037/1089-2680.9.3.203

Delle Fave, A. D., Brdar, I., Freire, T., Vella-Brodrick, D., \& Wissing, M. (2011). The eudaimonic and hedonic components of happiness: Qualitative and quantitative findings. Social Indicators Research, 100, 185-207. https://doi.org/10.1007/s11205-010-9632-5

Donaldson, S. I., Csikszentmihalyi, M., \& Nakamura, J. (2011). Applied positive psychology: Improving everyday life, health, schools, work, and society. London, England: Routledge Academic. 
Donaldson, S. I., Dollwet, M., \& Rao, M. A. (2015). Happiness, excellence, and optimal functioning revisited: Examining the peer-reviewed literature linked to positive psychology. The Journal of Positive Psychology, 10, 185-195. https://doi.org/10.1080/17439760.2014.943801

Donaldson, S. I., \& Ko, I. (2010). Positive organizational psychology, behavior, and scholarship: A review of the emerging literature and evidence base. The Journal of Positive Psychology, 5, 177-191. https://doi.org/10.1080/17439761003790930

Eloff, I., Achoui, M., Chireshe, R., Mutepfa, M., \& Ofovwe, C. (2008). Views from Africa on positive psychology. Journal of Psychology in Africa, 18, 189-194.

Fineman, S. (2006). On being positive: Concerns and counterpoints. Academy of Management Review, 31, 270-291. https://doi.org/10.5465/amr.2006.20208680

Gable, S. L., \& Haidt, J. (2005). What (and why) is positive psychology?. Review of General Psychology, 9, 103-110. https://doi.org/10.1037/1089-2680.9.2.103

Hackman, J. R. (2009). The perils of positivity. Journal of Organizational Behavior, 30, 309-319. https://doi.org/10.1002/job.587

Ho, S. M., Chan, C. L., \& Ho, R. T. (2004). Posttraumatic growth in Chinese cancer survivors. PsychoOncology, 13, 377-389. https://doi.org/10.1002/pon.758

Hobfoll, S. E., Johnson, R. J., Canetti, D., Palmieri, P. A., Hall, B. J., Lavi, I., \& Galea, S. (2012). Can people remain engaged and vigorous in the face of trauma? Palestinians in the West Bank and Gaza. Psychiatry, 75, 60-75. https://doi.org/10.1521/psyc.2012.75.1.60

Hobfoll, S. E., Palmieri, P. A., Johnson, R. J., Canetti-Nisim, D., Hall, B. J., \& Galea, S. (2009). Trajectories of resilience, resistance, and distress during ongoing terrorism: The case of Jews and Arabs in Israel. Journal of Consulting and Clinical Psychology, 77, 138-148. https://doi.org/10.1037/a0014360

Hofstede, G. (1984). Culture's consequences: International differences in work-related values (Vol. 5). Newbury, CA: Sage.

Kállay, É. (2008). Investigation of the relationship between religious growth, positive affect, and meaning in life in a sample of female cancer patients. Cognition, Brain, Behavior, 12, 161-182.

Keyes, C. L. M. (2003). Complete mental health: An agenda for the 21st century. In C. L. M. Keyes \& J. Haidt (Eds.), Flourishing: Positive psychology and the life well-lived (pp. 293-290). Washington, DC: American Psychological Association. https://doi.org/10.1037/10594-013

King, L. A., Heintzelman, S. J., \& Ward, S. J. (2016). Beyond the search for meaning: A contemporary science of the experience of meaning in life. Current Directions in Psychological Science, 25, 211-216. https://doi.org/10.1177/0963721416656354

Kormi-Nouri, R., Farahani, M. N., \& Trost, K. (2013). The role of positive and negative affect on wellbeing amongst Swedish and Iranian university students. The Journal of Positive Psychology, 8, 435-443. https://doi.org/10.1080/17439760.2013.823511

Lies, J., Mellor, D., \& Hong, R. Y. (2014). Gratitude and personal functioning among earthquake survivors in Indonesia. The Journal of Positive Psychology, 9, 295-305. https://doi.org/10.1080/17439760.2014.902492

Luthar, S. S., \& Cicchetti, D. (2000). The construct of resilience: A critical evaluation and guidelines for future work. Child Development, 71, 543-562. https://doi.org/10.1111/1467-8624.00164

Moher, D., Liberati, A., Tetzlaff, J., \& Altman, D. G. (2009). Preferred Reporting Items for Systematic Reviews and Meta-analyses: The PRISMA Statement. PLoS Med, 6, 7, e1000097. https://doi.org/10.1371/journal.pmed1000097

Oaksford, K., Frude, N., \& Cuddihy, R. (2005). Positive coping and stress-related psychological growth following lower limb amputation. Rehabilitation Psychology, 50, 266-277. https://doi.org/10.1037/0090$\underline{5550.50 .3 .266}$

Pecoraro, A., Mimiaga, M. J., O'Cleirigh, C., Safren, S. A., Blokhina, E., Verbitskaya, E., . . \& \& Woody, G. (2014). Lost-to-care and engaged-in-care HIV patients in Leningrad Oblast, Russian Federation: Barriers and facilitators to medical visit retention. AIDS Care, 26, 1249-1257. https://doi.org/10.1080/09540121.2014.897910 
Rao, M. A., \& Donaldson, S. I. (2015). Expanding opportunities for diversity in positive psychology: An examination of gender, race, and ethnicity. Canadian Psychology/Psychologie Canadienne, 56, 271-282. https://doi.org/10.1037/cap0000036

Rao, M. A., Donaldson, S. I., \& Doiron, K. M. (2015). Positive psychology research in the Middle East and North Africa. Middle East Journal of Positive Psychology, 1, 60-76.

Reitmaier, T., Bidwell, N. J., \& Marsden, G. (2011). Situating digital storytelling within African communities. International Journal of Human-Computer Studies, 69, 658-668. https://doi.org/10.1016/j.ijhcs.2010.12.008

Richardson, G. E. (2002). The metatheory of resilience and resiliency. Journal of Clinical Psychology, 58, 307-321. https://doi.org/10.1002/jclp.10020

Rusk, R. D., \& Waters, L. E. (2013). Tracing the size, reach, impact, and breadth of positive psychology. The Journal of Positive Psychology, 8, 207-221. https://doi.org/10.1080/17439760.2013.777766

Seligman, P., \& Csikszentmihalyi, M. (2000). Positive psychology: An introduction. American Psychologist, 55, 5-14. https://doi.org/10.1037/0003-066X.55.1.5

Selin, H., \& Davey, G. (2012). Happiness across cultures: Views of happiness and quality of life in non-Western cultures. New York, NY: Springer Science + Business Media. https://doi.org/10.1007/978-94-007-2700-7

Shapira, L. B., \& Mongrain, M. (2010). The benefits of self-compassion and optimism exercises for individuals vulnerable to depression. The Journal of Positive Psychology, 5, 377-389. https://doi.org/10.1080/17439760.2010.516763

Shek, D. L., Sun, R. F., \& Merrick, J. (Eds.). (2013). Positive youth development: Theory, research and application. Hauppauge, NY: Nova Science.

Sheldon, K. M., Kashdan, T. B., \& Steger, M. F. (2011). Designing positive psychology: Taking stock and moving forward. New York, NY: Oxford University Press. https://doi.org/10.1093/acprof:oso/9780195373585.001.0001

Shiota, M. N., Yee, C. I., O’Neil, M. J., \& Danvers A. F. (2017). Positive emotions. In M. A. Warren \& S. I. Donaldson (Eds.), Scientific advances in positive psychology (pp. 37-71). Santa Barbara, CA: Praeger.

Solano, A. C. (2014). Positive psychology in Latin America. New York, NY: Springer Science + Business Media. https://doi.org/10.1007/978-94-017-9035-2

Strümpfer, D. W. (2005). Standing on the shoulders of giants: Notes on early positive psychology (psychofortology). South African Journal of Psychology, 35, 21-45. https://doi.org/10.1177/008124630503500102

Tedeschi, R. G., Blevins, C. L., \& Riffle, O. M. (2017). Posttraumatic growth: A brief history and evaluation. In M. A. Warren \& S. I. Donaldson (Eds.), Scientific advances in positive psychology (pp. 131163). Santa Barbara, CA: Praeger.

Vallerand, R. J., Blanchard, C., Mageau, G. A., Koestner, R., Ratelle, C., Léonard, M., ... \& Marsolais, J. (2003). Les passions de l'ame: On obsessive and harmonious passion. Journal of Personality and Social Psychology, 85, 756-767. https://doi.org/10.1037/0022-3514.85.4.756

Vallerand, R. J., Ntoumanis, N., Philippe, F. L., Lavigne, G. L., Carbonneau, N., Bonneville, A., . . \& Maliha, G. (2008). On passion and sports fans: A look at football. Journal of Sports Sciences, 26, 12791293. https://doi.org/10.1080/02640410802123185

Vázquez, C., \& Hervás, G. (2010). Perceived benefits after terrorist attacks: The role of positive and negative emotions. The Journal of Positive Psychology, 5, 154-163. https://doi.org/10.1080/17439761003630060

Vázquez, J. J. (2013). Happiness among the garbage: Differences in overall happiness among trash pickers in León (Nicaragua). The Journal of Positive Psychology, 8, 1-11. https://doi.org/10.1080/17439760.2012.743574

Warren, M. A., \& Donaldson, S. I. (Eds.) (2018). Positive psychology of relationships: New directions in theory and research. Santa Barbara, CA: Praeger.

Warren, M. A., Donaldson, S. I., \& Lee, J. Y. (2018). Applying positive psychology to advance relationship science. In M. A. Warren \& S. I. Donaldson (Eds.), Positive psychology of relationships: New directions in theory and research (pp. 9-34). Santa Barbara, CA: Praeger. 
Warren, M. A., Donaldson, S. I., \& Luthans, F. (2017). Taking positive psychology to the workplace: Positive organizational psychology, positive organizational behavior, and positive organizational scholarship. In M. A. Warren \& S. I. Donaldson (Eds.), Scientific advances in positive psychology (pp. 195-227). Santa Barbara, CA: Praeger.

Watkins, P. C., \& Bell, J. (2017). Current theories and research in the psychology of gratitude. In M. A. Warren \& S. I. Donaldson (Eds.), Scientific advances in positive psychology (pp. 103-129). Santa Barbara, CA: Praeger.

Wood, L., Theron, L., \& Mayaba, N. (2012). "Read me to resilience:" Exploring the use of cultural stories to boost the positive adjustment of children orphaned by AIDS. African Journal of AIDS Research, 11, 225-239. https://doi.org/10.2989/16085906.2012.734982

Yehuda, R. (2002). Post-traumatic stress disorder. New England Journal of Medicine, 346, 108-114. https://doi.org/10.1056/nejmra012941 